\title{
The Use of Knowledge Management-Based Information Collaborative Learning Tool in English Teaching Classroom
}

\author{
Liying Wei $\mathbb{D},{ }^{1}$ Chao Shang, ${ }^{2}$ and Xiaoqiu Chen ${ }^{3}$ \\ ${ }^{1}$ Institute of Foreign Languages, China Medical University, Shenyang Liaoning 110112, China \\ ${ }^{2}$ Network Center of China Medical University, Shenyang Liaoning, 110122, China \\ ${ }^{3}$ Department of Otolaryngology, China Medical University Shengjing Hospital, Shenyang Liaoning 110015, China \\ Correspondence should be addressed to Liying Wei; lywei@cmu.edu.cn
}

Received 11 November 2021; Accepted 22 December 2021; Published 27 January 2022

Academic Editor: Narasimhan Venkateswaran

Copyright (c) 2022 Liying Wei et al. This is an open access article distributed under the Creative Commons Attribution License, which permits unrestricted use, distribution, and reproduction in any medium, provided the original work is properly cited.

In the recent digitization era, knowledge management plays a significant role in the teaching and learning process. Collaborative learning is becoming a trending technology in enhancing the learning process by the concept of "learning through working together." This learning methodology will make the students learn the courses faster. This research work focuses on applying collaborative learning tools in the learning process of English education in classrooms. Also, knowledge management is focused on in this research work. Multiprocessor learning algorithm (MLA) with support vector machine (SVM) is implemented over the student response. The students' responses indicate that the students have gained much knowledge with the English education-learning technology from collaborative learning compared to the traditional learning method.

\section{Introduction}

Organizational research thrives when people can learn and work together. Virtual Learning Environments (VLEs), or e-learning (EL), are increasingly being used by a growing number of educational institutions to foster collaboration. Using a Virtual Learning Environment (VLE) allows students to collaborate and share knowledge, which is sometimes referred to as "knowledge management" (KM). Just like a content management system (CMS), it serves as a repository of knowledge. For the sake of collaboration, however, knowledge must be gathered and shared. This platform allows for the acquisition and distribution of knowledge. In other words, KM focuses on the absence of information exchange within an organization, and its primary goal is to improve this situation [1]. EL emphasizes self-directed, independent learning, whereas integrating KM with EL fosters a more group-oriented setting. Knowledge spreads over the world as a result of this. Structured learning content in EL allows the user to learn about a specific topic.
In contrast, search and sort functionality in KM allows users to collaborate on various topics via a content management system (CMS). Traditionally, an EL system under knowledge management (KM) has been viewed as a knowledge repository that can use KM methodologies to improve knowledge distribution [2]. The phrases "integration" and "adoption" are used interchangeably to describe the relationship between the KM and EL domains. "Integration" is a term used to indicate when the two disciplines are working in tandem. Using the word "adoption" means adapting methods and tools from another field to improve effectiveness [3]. KM technologies are vital for extending the boundaries of the EL system to include a broader range of communities. If you want your employees to learn at their own pace on their terms, you need to integrate learning management systems (LMS) with educational technology (ELT). The ability to rapidly expand one's knowledge base necessitates a collaborative learning environment.

In contrast to traditional classroom learning, e-learning (EL) emphasizes one-on-one instruction [4]. The knowledge 
that is difficult to convey in words must be put into physical form to be shared. Tacit knowledge is codified into physical or explicit form to learn through knowledge management (KM). EL systems offer preformatted educational content and tools.

Learners are helped in developing their knowledge through the use of intercommunication possibilities on specific themes. However, knowledge management systems (KMS) deliver knowledge through CMSs, which feature search and sort capabilities and also the ability to collaborate with experts and other users on a wide range of subjects [5]. Learning and knowledge management (KM) procedures can be integrated to produce synergies that considerably boost the generation of new knowledge and the efficiency of learning processes [6]. There are many ways to combine the two, but they all revolve around fundamental knowledge management techniques. Integration of knowledge management and educational technology (KM and EL) has become an inevitable trend in facilitating self-directed, just-in-time learning and the development of shared corporate knowledge [7], tacit knowledge codification, i.e., physical codification of human knowledge. Knowledge can only be helpful if accompanied by explicit knowledge, which cannot separate from learning. Knowledge cannot be disseminated to the general public without codification. Knowledge management (KM) is an area of artificial intelligence (AI) that makes it easier to organize and store information. KM's expert system (ES) governs a set of rules for codification, which is done through coding.

EL learners face the problem of acquiring new knowledge from current knowledge, which can only be done through knowledge sharing. With the help of various internet-based tools and technologies like podcasts and audio/video conferences, students are allowed to participate in collaborative learning. They can learn together with various internet-based tools and technologies such as podcasts [8]. In addition to online discussion forums, live chat, email, and so on, these tools also help to improve collaboration. Capturing knowledge is the first step to acquiring and sharing knowledge. Implicit and explicit knowledge is converted to and from each other to facilitate knowledge acquisition. Tacit knowledge can be codified into formal language by an expert system (ES) and made available in learning content. Educators can share this information [9]. During education, each learner is capable of acquiring new knowledge. Another critical part of learning is the documentation of content, which is done by recording information. Databases and document management systems are used to store information in the EL system.

Web tools such as wikis, tagging, social networking (Facebook, Twitter, etc.), big data, and linked data, are used to store and retrieve knowledge in the EL context. To verify the accuracy and correctness of knowledge learned, periodical evaluations of students' knowledge are necessary. Both subjective and objective evaluation approaches are available for conducting the assessments [10]. The use of assignments, midterms, and final exams is an example of a subjective procedure. Verbal and nonverbal tactics such as group discussion and observational techniques such as attendance are all examples of objective methods. It is possible to submit assignments and take quizzes via Facebook, email, and other web-based tools and technologies, including Skype and live chat, as well as video conferencing. One of the essential parts of increasing literacy in an EL setting to achieve economic growth is the application of knowledge [11]. Cooperative exchange of knowledge can be achieved through online discussion forums, in-person lectures, or mashups. Even though personal knowledge management is not a new concept, it has become increasingly significant over the past few years. Although human beings' ability to get knowledge is expanding, they are still limited in processing information. As a result of computers, communications, and networks, personal knowledge management is possible [12] - the ability of individuals to properly manage information. Applying appropriate skills and tools to manage personal knowledge is essential for success. The researcher stated that applying AI to personal $\mathrm{KM}$ is necessary to obtain accurate and timely information [13]. The use of intelligent search can minimize the number of results returned by a search engine and increase the relevancy of the results. Artificial neural networks (ANNs) have been presented to improve the performance of existing search engines. With practice and examples, an algorithm can search for information based on the content, meaning, and context of a given piece of writing.

Unstructured data can be effectively managed by automatic classification of knowledge [14]. Knowledge categorization can be broken down into themes and subthemes, giving a hierarchical structure for classifying knowledge. To find the most statistically related documents, a statistical software program is used. New papers can be classified using induced rules. Information technology is the basis of knowledge management and information collaborative learning. The discovery, storage, and dissemination of knowledge cannot rely on the original methods as before with the continuous expansion of information and the increasing enrichment of knowledge [15]. The development of information technology and network technology provides new ideas for discovering, storing, and disseminating knowledge. Hence, the popularization and application of information technology are an inevitable choice to complete knowledge management effectively, reasonably, and systematically. This new collaborative learning model must rely on information technology to develop effectively, which is a technical problem and indispensable. They all have a process of learning knowledge. For knowledge management, knowledge is only a part of knowledge management, while it can be taken as the whole of collaborative learning for information collaborative learning [16]. Both have a cognitive process of knowledge, which is a crucial part of knowledge management. The core idea of knowledge management and information collaborative learning is that they support each other in technology and learn in concept. Knowledge management is adopted to mine and reintegrate knowledge, integrate it into collaborative learning, and identify, acquire, share, and store knowledge based on collaborative learning. This study focused on implementing knowledge management-based collaborative learning in the English classroom. 


\section{Methods and Data}

Information collaborative learning is a strategy to organize students to study in groups. Teamwork is an indispensable part of achieving class learning objectives. The core purpose of the collaborative learning model is to strengthen students' understanding and mastery of knowledge. Its core idea is to establish collaborative groups [17]. Generally, the collaborative team mainly has four components: team members, teachers, knowledge resource base, and network environment. The collaborative group has a loose structure. As the most fundamental component of the collaborative learning model, its division has specific standards. Members of collaborative learning groups can participate in learning and discuss under different cultural backgrounds and fields. In addition, online teachers will regularly investigate the learning situation of team members, assess the students' achievements, issue learning achievement certificates, and so on.

Online teachers can be full-time teachers or experts, responsible for organizing problems, evaluating collaborative learning results, managing discussions, supervising learners' collaborative learning process, and giving learners some guidance [18]. The traditional teaching model also radiates a powerful force because of the use of this teaching resource. Meanwhile, in collaborative learning activities, these rich teaching resources also laid a good foundation for online collaborative learning. Environment mainly includes hardware environment and organizational environment.

As the world is facing an information technology revolution, the most effective can be seen in the educational sector. The learning of the theoretical and the practical subjects has become simpler with this revolution. The proposed system architecture is represented in Figure 1. This architecture represents an image for the digital or modified traditional classroom, sample collaborative learning, system administrator, database, teacher, and students. The working concept behind collaborative learning is "learning through working together." In this learning methodology, courses are studied by sharing the learned information among the students under the teacher's supervision. This process will make the students understand the concepts more accessible, and they gain much knowledge while sharing the information and the course materials. Digital classrooms are equipped with recent technologies in the classroom so that the teacher and students can easily access the available resources. This research focuses on the knowledge management of English education teaching and learning. Knowledge management should also focus on maintaining the resources in the database and easy retrieval of the data from the database. Multiprocessor learning algorithm (MLA) with support vector machine (SVM) is implemented to classify the resources and give access privileges to the corresponding teachers and the students. Teachers play a significant role in the course material preparation, monitoring the students during the course and through assessment, encouraging the students to attend the complete course and the given assessments. The privileged students will be given access to the course materials for offline utilization, learn the lesson, attend the assessments, and provide feedback to the attended courses.
All the communications will be updated in the database. They will provide automatic notifications to the teachers with the aid of artificial intelligence technology by treating each active participant as the node for accessing the resource with mobile applications. The government or private universities can define mobile applications for the usage of the teachers and the students. When the teacher or the student is facing any issues accessing the course materials, the system administrator will inform the system administrator through the application accessed by them. The respective measures will be made by the administrator and will be notified to the person. Digitization and visualization of the course materials have made the teaching and the learning process of the theory-based course easier. This method has also increased student and teacher interaction with improved performance in the student results. These improved results of the students and the teachers' performance have made the colleges and universities introduce new courses which will be helpful to the students after the courses. English education-learning technology is introduced to automate teaching and learning of the English course and automatically activate the assessment when the student completes the online courses. Artificial intelligence will be utilized with an automated evaluation of the submitted assessment, and the scores are updated to make this process successful. The assessment can be objective or of varying types as decided by the teacher. The teacher will prepare questions and answers uploaded for automatic evaluation. The teacher will also determine the duration of the assessment and, after submission, make a further evaluation to prepare the performance analysis of the students. The machine learning algorithm has been implemented to evaluate the performance of collaborative-based learning towards English education.

Collaborative learning, inside which students work together to produce a shared understanding of concepts, is a well-established education with significant potential in the English teaching classroom. Students acquire a more prosperous recognition for a subject through discussion and challenge each other's ideas than through isolation study or educational teaching methods. Nevertheless, for collaborative learning to be successful, a tiny framework by a teacher is required. The application of collaborative learning techniques in teaching classrooms in English teaching, indicating its application in English teaching, is restricted to the deadline. However, the potential for collaborative learning perspectives to establish personality the student already knows is significant, so collaborative learning must be highly recognized as a suitable teaching method for teaching the classroom.

The multiprocessor learning algorithm (MLA) would be implemented to a support vector machine (SVM), as well as the classification algorithm of integrated modules will be initiated within the SVM structure. In particular, we would first describe the graph's construction method as well as the corresponding optimization method predicated on semisupervised multiprocessor learning.

$$
\partial_{1}\|d\|^{2} \leq \int_{r_{0}}^{r_{0}+R_{0}}\left|U^{R}(\tau) d\right|^{2} a b(\tau) \leq \partial_{2}\|d\|^{2}, \forall_{r 0} \geq 0, r \in C^{p} .
$$




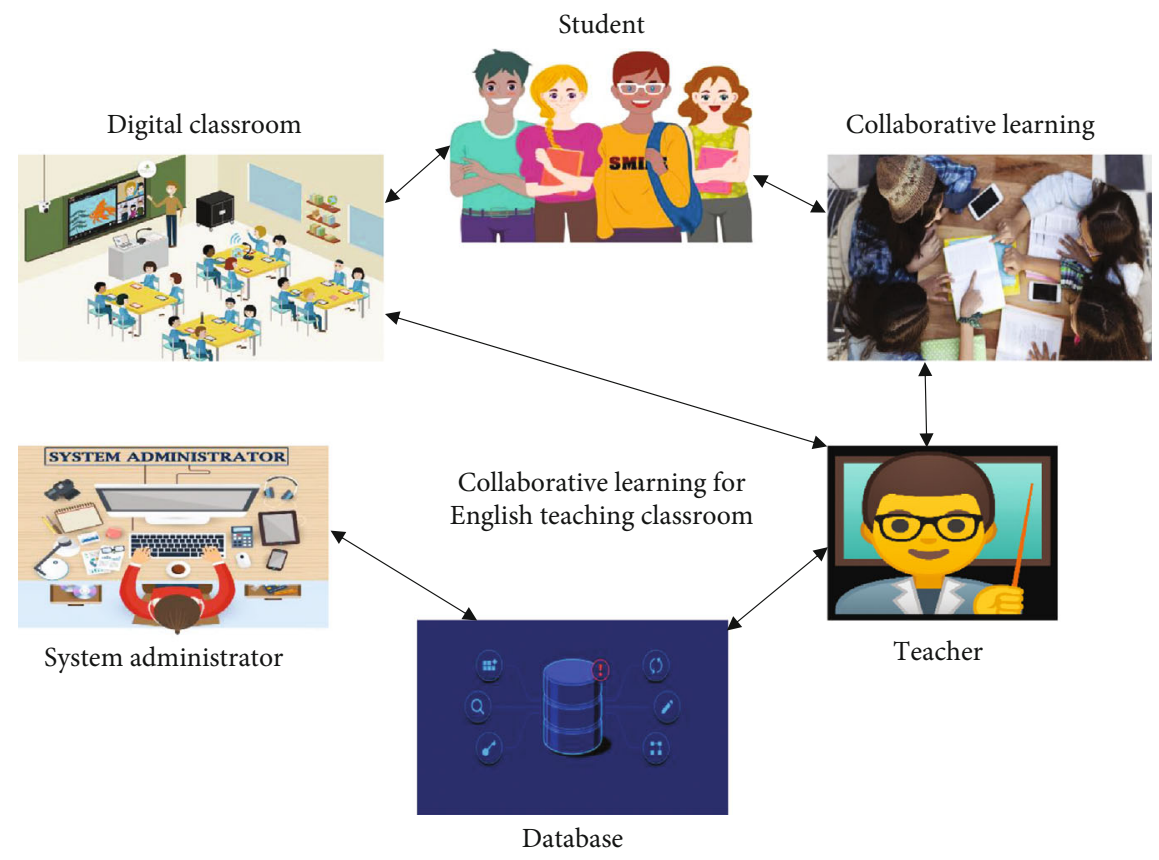

Figure 1: Proposed architecture for collaborative learning.

The sophistication of the computation grows dramatically as the $\partial_{1}\|d\|^{2}$ structures lengthen throughout this method of probability computation as given in Equation (1). The model's parameters $\left|U^{R}(\tau) d\right|^{2} a b(\tau) \leq \partial_{2}\|d\|^{2}, \forall_{r 0} \geq 0$, are nearly impossible to quantify on current hardware. The presence $f^{p}(r)$ (Equation (2)) of such a sentence is determined solely by the word preceding it, i.e., the English language framework is given in the following equation.

$$
f^{p}(r)=\lim _{g \longrightarrow 0} \frac{1}{g^{p}} \sum_{q=0}^{p}(-1)^{q}\left(\begin{array}{l}
p \\
q
\end{array}\right) f(r-q g) .
$$

The likeness of a sentence is determined solely by -sent $\left(\left(\nabla^{a} x\right) /\left(\left|\nabla^{a} x\right|+g\right)\right)$, the two or more words preceding it, and $g$ is the corresponding optimization method predicated on semisupervised multiprocessor learning, i.e., the English language framework, and is represented as in the following equation.

$$
-\operatorname{sent}\left(\frac{\nabla^{a} x}{\left|\nabla^{a} x\right|+t}\right)+\lambda_{e}\left(x-x^{0}\right)=0 .
$$

The distinction between the learner's cognitive stage and the level of difficulty to learning materials is represented by $q_{i}(h)$, and the student's language level objective is shown in the following equation.

$$
q_{i}(h)=\frac{f_{i} r_{i}-\operatorname{bad}(h)}{\operatorname{good}(h)-\operatorname{bad}(h)} .
$$

The distinction between helps the audience understand enclosed learning resources and the knowledge notes the learner wants to acquire is represented by $E_{i}^{n}(r)$ (refer to Equation (5)), the learner's progress. The relatively smaller a distinction is, the more closely the learning resource's expertise points match $\operatorname{randam}_{j} E_{i j}^{n}(r)$ the learner's knowledge points is in Equation (5).

$$
E_{i}^{n}(r)=\sum_{j \in L} \operatorname{randam}_{j} E_{i j}^{n}(r)
$$

The overall spending information among teaching material is represented in Equation (6) by $(u, w ; A, \phi)$, the optimization problem of expenditure with both educational materials.

$$
(u, w ; A, \phi)=|d|^{-0.6} \int_{-\infty}^{+\infty} d(\tau) h(\tau-r) e^{-j b \tau} d \tau
$$

Knowledge management-based information is used as a collaborative learning tool in English teaching classrooms. So, we fixed the threshold value based on the network frequency. And we are able to use -0.6 after the online classroom to get the exact result.

The primary function learning period $L_{p p}(u)$ of Equation (7) represents the goals that highlight the differences between the learning time needed to complete the educational materials $b_{i} U_{i}(u)=B^{R} U(u)$ and also the learning detection time.

$$
L_{p p}(u)=\sum_{i=1}^{P} b_{i} U_{i}(u)=B^{R} U(u) .
$$

The learner's total optimization performance and also $\phi \Phi_{\mathrm{q}, \mathrm{p}}$, the learning route, created by the comment section 


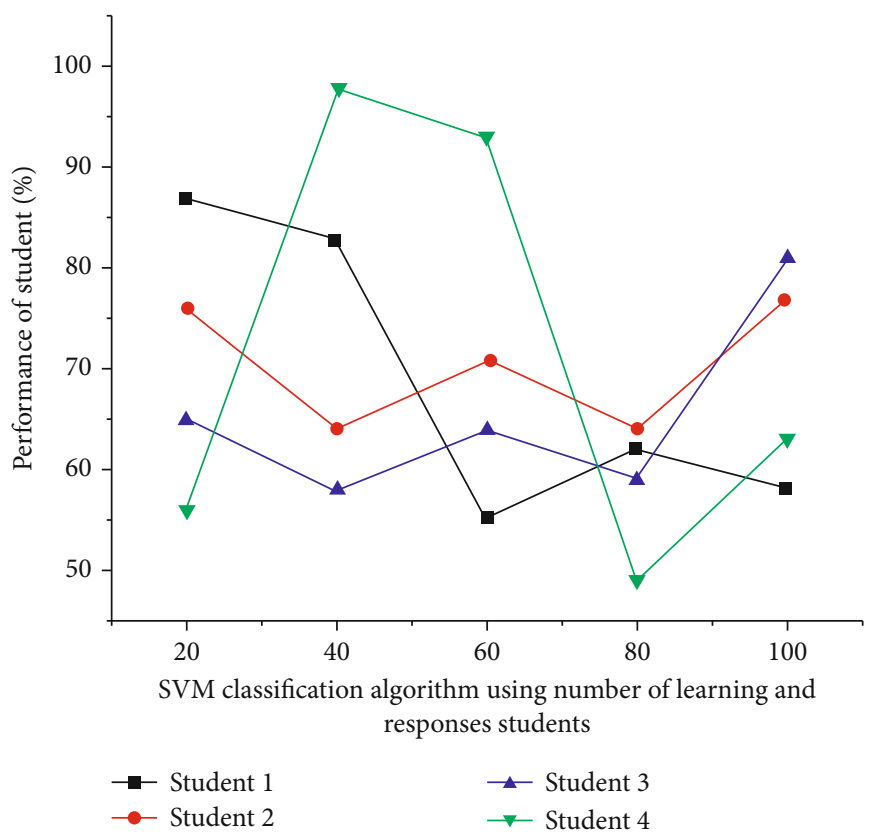

Figure 2: Performance analysis for number of student (per record 2000 data's) responses, motivation, and learning using the SVM algorithm with machine learning.

function via recalculating coefficients, are expressed by Equation (8) that is a functional illustration of the personalized learning route optimization method.

$$
\Phi_{q, p}=\frac{\left\|Q_{q, p}\right\|^{2}}{\delta^{2}} \operatorname{exps}\left(\frac{\left(Q_{q, p} * A\right)}{3 \delta^{2}}\right) *\left[e^{i\left(Q_{q, p} * A\right)}-e^{-\frac{\delta^{2}}{3}}\right] .
$$

The algorithm $\varphi$ also divides the notification of a particular direction of propagation into three stages: speed resistance, self-learning, and social behavior. The $\left(\sum_{i=1}^{O} Q_{i} P_{i}\right) / U\left(Q_{i} \in Q\right)$ stance update of a substance within generation has been decided by a particle's stance $t$ creation, and the generation is going in the direction of motion, as detailed in the following equations.

$$
\begin{gathered}
e=\frac{\left(\varphi \Phi_{35}+\varphi \Phi_{04}\right)^{2}+4 \varphi \phi_{22}^{2}}{\left(\varphi \Phi_{35}+\varphi \Phi_{04}\right)^{2}}, \\
B=\frac{\sum_{i=1}^{O} Q_{i} P}{\sum_{i=1}^{O} P_{i}}=\frac{\sum_{i=1}^{O} Q_{i} P_{i}}{U}\left(Q_{i} \in Q\right) .
\end{gathered}
$$

From the standpoint of $Q^{\prime \prime}$ possibility, the state of the $\partial K / \partial u$ particle has been defined. Each particle's $q^{\prime \prime}$ bit value within a subspace is 0 or 1 , and the equation is just as described in the following equations.

$$
Q^{\prime \prime}=\left\{Q^{\prime \prime} \mid q^{\prime \prime}=\frac{q^{\prime} \times n}{N}, \forall q^{\prime} \in Q^{\prime}\right\}
$$

$$
\frac{\partial K}{\partial u}=\sum_{i=1}^{p}\left[h_{i}-\frac{\operatorname{exps}\left(u+\sum_{j=1}^{q} u_{i j} \beta_{j}\right)}{1+\operatorname{exps}\left(u+\sum_{j=1}^{m} u_{i j} \beta_{j}\right)}\right]=0 .
$$

Machine learning is a representation, and each texture relates a transformation technique to the surface $T \in S^{N \times D}$ preceding it, referred to as nontransformation to an edge previous it. $M^{p} \in S^{d_{p-1 \times d_{p}}}$ is used to achieve a $d_{p}$ directional recognition $p-1, T_{p-1} \in S^{N \times d_{p-1}}$, a matrix able to represent a linear transformation applicable to a layer $p-1$ production to receive a $d_{p}$ dimensional recognizing $T_{p-1} M^{p} \in S^{N \times d_{p}}$. These are calculated using the following equation.

$\phi\left(T, M^{1}, \cdots, M^{k}\right)=\psi_{K}\left(\psi_{K-1}\left(\cdots \psi_{2}\left(\psi_{1}\left(T M^{1}\right) M^{2}\right) \cdots M^{p-1}\right) M^{p}\right)$.

It should be noted that it is an $A \times B$ matrix, in which $B$ $=d_{p}$ is the aspect of the network's output, which is really similar to the quantity of classes with a specific circumstance of a classification model with the function as in Equation (14).

$$
\left.\min _{\left\{M^{p}\right\}_{p=1}^{P}} l, \Phi\left(H, M^{1}, \cdots, M^{P}\right)\right)+\lambda \Theta\left(M^{1}, \cdots, M^{p}\right)
$$

in which $h_{i}(T)$ defines a specific various possible stem disciplines in response to generating precise $X$ in an unlimited dimensional space $h_{i}(T) \in V$ between all hidden alternative machine activation functions as in the following equation.

$$
\left\{T_{i} \in D^{2}(\Omega), H_{i}=f\left(T_{i}\right)\right\}_{i \in I} .
$$


TABle 1: Performance result analysis for number of student (per record 2000 data's) responses, motivation, and learning using the SVM algorithm with machine learning.

\begin{tabular}{lcccc}
\hline $\begin{array}{l}\text { No. of response in learning } \\
\text { questionnaire }\end{array}$ & $\begin{array}{c}\text { Student data 1 (2000 } \\
\text { records) }\end{array}$ & $\begin{array}{c}\text { Student data 2 (2000 } \\
\text { records) }\end{array}$ & $\begin{array}{c}\text { Student data 3 (2000 } \\
\text { records) }\end{array}$ & $\begin{array}{c}\text { Student data 4 (2000 } \\
\text { records) }\end{array}$ \\
\hline 20 & 87 & 76 & 65 & 56 \\
40 & 83 & 64 & 58 & 98 \\
60 & 55 & 71 & 64 & 93 \\
80 & 62 & 64 & 59 & 49 \\
100 & 58 & 77 & 81 & 63 \\
\hline
\end{tabular}

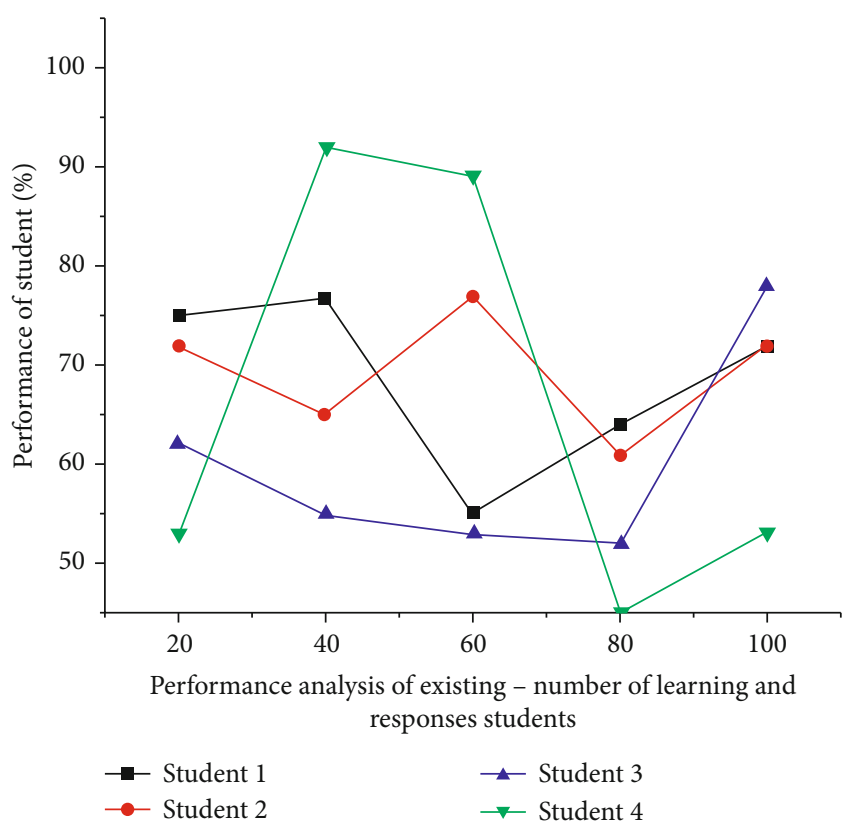

Figure 3: Performance analysis of existing system for number of student (per record 2000 data) responses in learning.

As a result, machine learning methods apply data that is normally distributed and predictable to locally transcribe. A SVM is composed of several convolutional networks of the type $T=B M(T)$ that act on a $p$-dimensional input $T(u)=($ $T 1(u), \cdots, T p(u))$ by employing an institution of filtration ( $w 1,10), l=1, \cdots, q, l 0=1, \cdots, p$, and the argument of multiconsistency $\psi$ is shown as follows.

$$
\widetilde{T_{l}}(u)=\psi\left(\sum_{p=1}^{p}\left(T_{l} \times w l . v\right)(u)\right) .
$$

Creating a $q$-dimensional result, $T(u)=(T 1(u), \cdots, T q($ $u))$ is an alternative name again for features extracted.

$$
(T \times w)(u)=\int_{\Omega} T\left(u-u^{\prime}\right) w\left(u^{\prime}\right) d u^{\prime}
$$

This symbol in Equation (17) represents the traditional transformation function. According to the deflection prior, the filters $M$ have compressed spatial support. $T=Z(T)$ is a

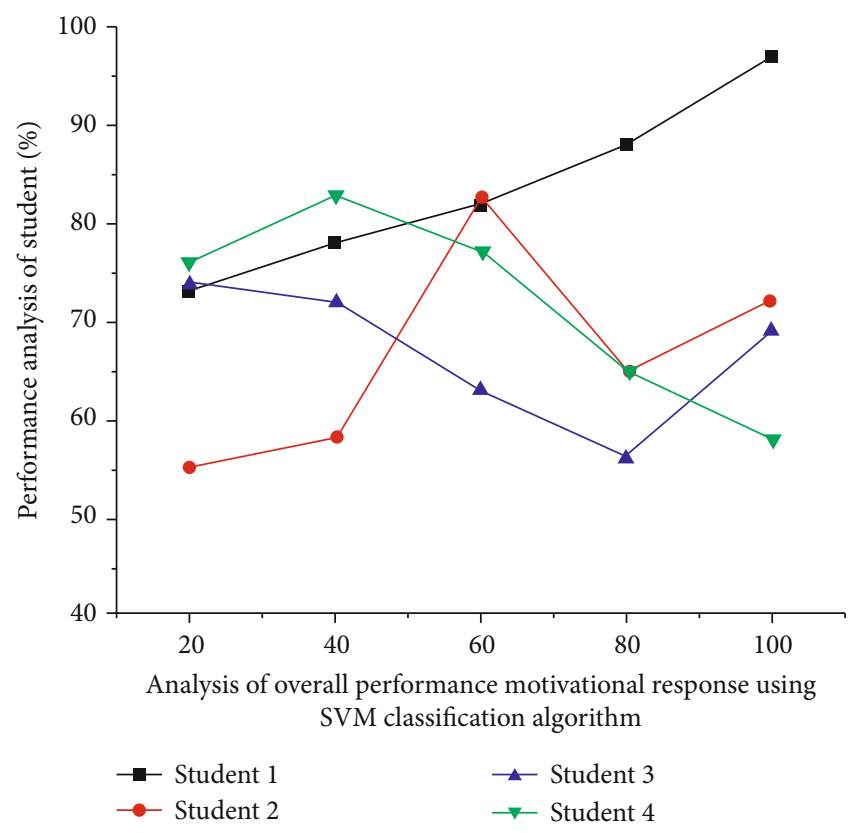

FIgURE 4: Analysis of overall performance for a large number of students (per record 2000 data points) motivational response using the SVM classification algorithm with machine learning (ML).

down testing process or convolution layers which can also be used as represented in the following equation.

$$
\widetilde{T_{l}}(u)=Z\left(\left\{T_{l}\left(u^{\prime}\right): u^{\prime} \in N(u)\right\}\right), l=1, \cdots . . q .
$$

\section{Results and Discussion}

Regarding the traditional English teaching method, teachers only introduce the contents of the textbook and do not expand the knowledge, leading to student's lack of interest in learning. In the practical research, it has been found that the student's initiative is not strong and the classroom atmosphere is not active in the traditional classroom English learning process; students even regard learning as a heavy work to perform. On the contrary, collaborative learning information solves this problem, making teachers become the leader and students become the masters of the classroom. Students are motivated to complete their tasks and get recognition from others to enhance their selfconfidence. In this process, learners are the main body of 


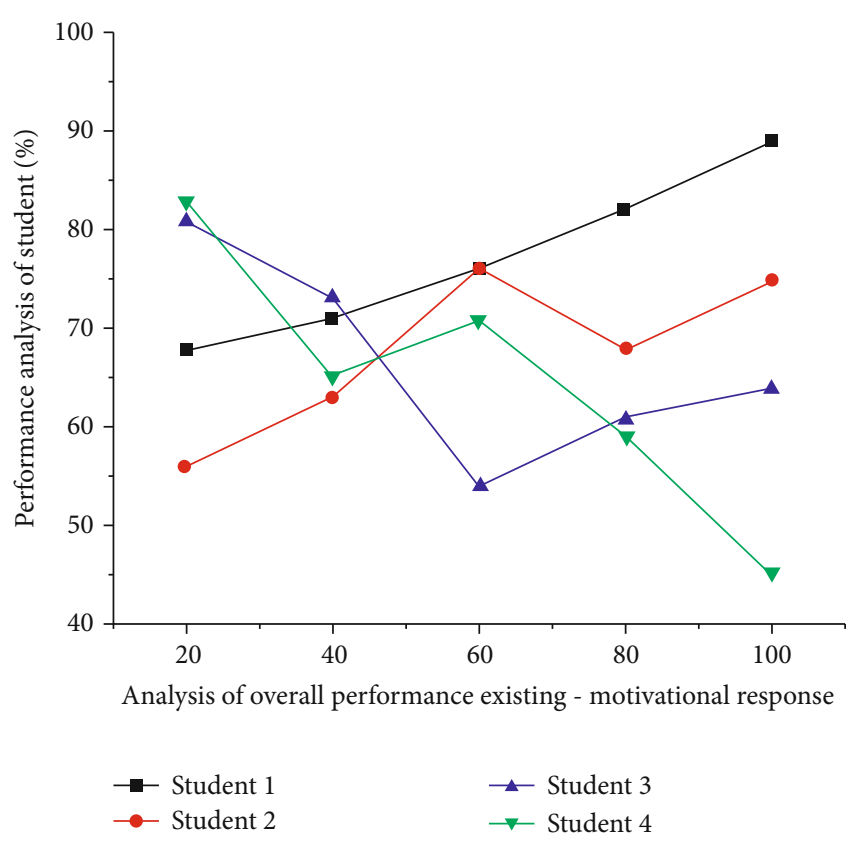

FIgURE 5: Overall performance analysis for the existing motivational response.

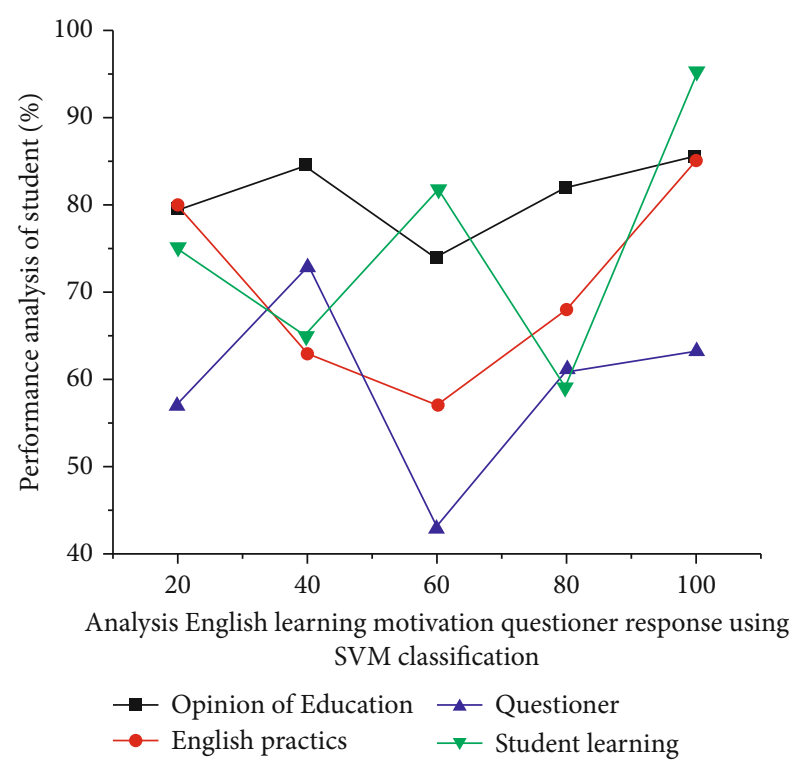

FIGURE 6: Overall performance analysis of English learning, motivation, questionnaire response using the SVM classification with ML techniques.

learning, and their internal potential has been brought into play. The whole classroom can reduce many passive factors in students' active learning state and better promote the communication between teachers and students as expressed in the following equation.

$$
(u)=Z\left(\left\{T_{l}\left(u^{\prime}\right): u^{\prime} \in N(u)\right\}\right), l=1, \cdots . . q
$$

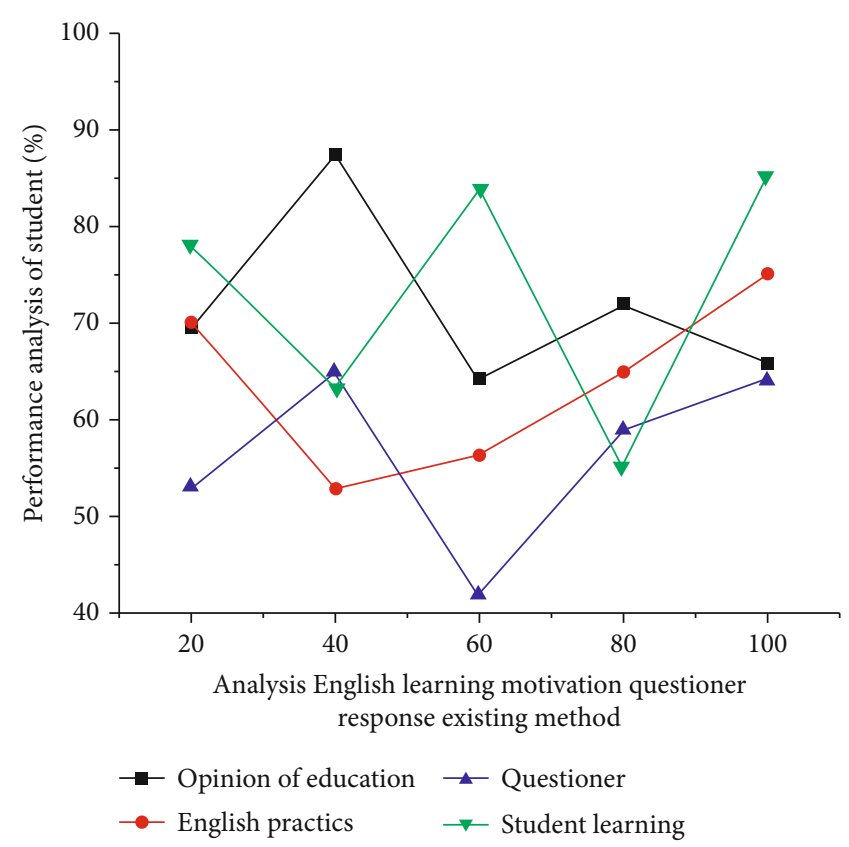

Figure 7: Performance analysis of English learning motivation questionnaire response result for existing method.

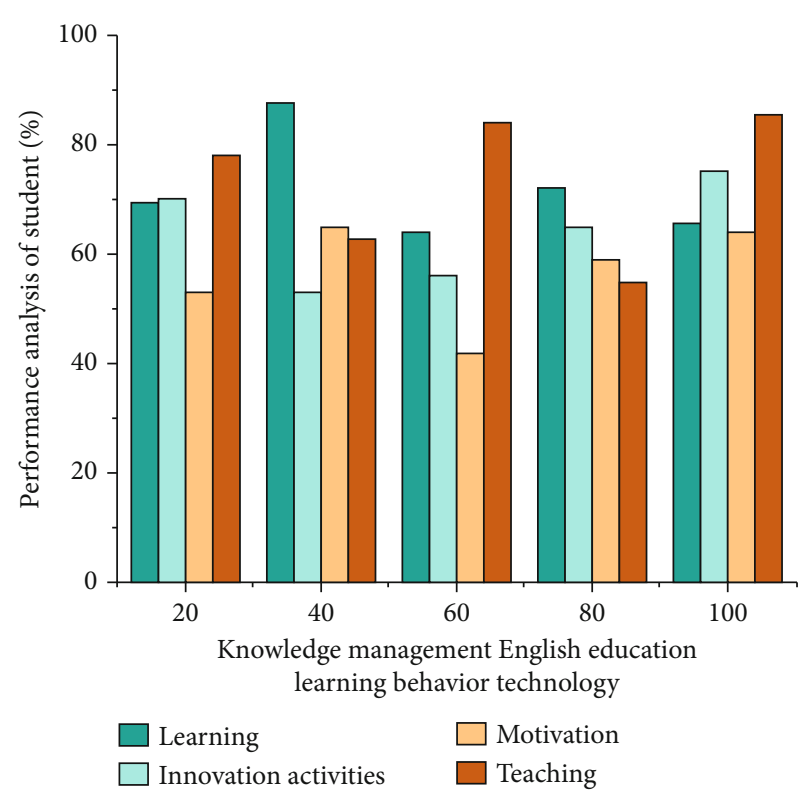

FIgURE 8: Pearson's correlation value for knowledge management as well as English education-learning behavior technology.

The English learning framework contains 2000 data for each student record. The behavior learning is an effective motivator with all participants (see Figure 2). This is associated with a recurring theme throughout the effective education spectrum using the SVM classification algorithm getting the best result. Group members' involvement in engaging learners may be directly proportional to personal observations. English teachers may benefit the most, though students are expected and encouraged to understand enough 
TABLE 2: Result analysis of knowledge management as well as English education-learning behavior technology.

\begin{tabular}{lcccc}
\hline Variable & Knowledge of management & $\begin{array}{c}\text { Average response } \\
\text { time (seconds) }\end{array}$ & $\begin{array}{c}\text { Maximum response } \\
\text { time (seconds) }\end{array}$ & $\begin{array}{c}\text { Teaching/learning of } \\
\text { innovation activities }\end{array}$ \\
\hline Knowledge of management & Pearson's association & 2.86 & 2.97 & 0.784 \\
Collaborative learning activities & Group work & 0.73 & 1.57 & 0.823 \\
\hline
\end{tabular}

of the assumption. The overall performance for each student record is $98 \%$ which helps classify the dataset and result shown in Table 1.

This is a recurring theme all through the effective education spectrum, with the existing work (refer Figure 3 ) performance producing the best results. Observations may be directly related to group members' involvement in involving learners. Although students are expected to know enough of the presumption to be encouraged, English teachers could benefit the most. To classify this same dataset, each student achieves an overall performance of $92 \%$. It is the same dataset used to compare the existing work and SVM classification based on the result to get the best result in the SVM classification algorithm with machine learning.

The majority of research on the development of curiosity focuses on the important education. Such analyses, on the other hand, can assist us in understanding how enthusiasm is becoming a motivation to become an increased specialist using the SVM classification with ML (refer to Figure 4). The distinction between evidential and conceptual genuine interest, which are exhibited by knowledge inquiry and motivational response for overall $97 \%$, can be seen, for example, whenever a child questions over a minor science issue, he has also increased emphasis on objects within the child's immediate area.

There is a large percentage of investigation and development of inquisitiveness focused on education. Those very analyses, on either hand, can help us understand how enthusiasm becomes a motivation to be a greater specialist by combining existing classification (refer to Figure 5). There is a difference between probative and theoretical real interest, as shown by knowledge inquiry as well as motivational responding overall result analysis for $92 \%$.

The students could have a positive experience of official English education for many years or more, but they can also be motivated across the vast English education data processing international syllabus. Learning organizations associated with active learning concept need to bring English topics to life in English education. Even though effective English teachers have been required, learning must be encouraged at all tiers of English education, with knowledge that future instructors will be one of the current population of students. The possibility of being a component of a discovery is certainly enticing for everybody, including students as well as English teachers. Overall performance analysis of English learning, motivation, and questionnaire response using SVM classification result for $97 \%$ with ML techniques (refer to Figure 6).

Students may have a good experience with official English education for more than decades, but they may also be motivated from across the huge English education data processing global syllabus. Learning organizations associated with the concept of active learning must bring English subjects to life in English education. The overall performance analysis of English learning and motivation of questionnaire response results for the existing overall method result is $89 \%$ (refer to Figure 7).

Figure 8 illustrates that there is a considerable relationship between organizational management, learning result (89\%), and teaching (activity, as well as innovative thinking). Like the result of the positive and statistically significant association, the function of knowledge management through enhancing students' and teachers' innovative thinking in classroom learning organizations can be illustrated (refer to Figure 8).

The coefficient of determination of 0.784 indicates a moderately good association (refer to Table 2). This demonstrates that there is a significant correlation between knowledge management as well as teaching and learning activity innovative thinking. As a result of the substantially good association, the role of knowledge management in enhancing innovation of teachers and students in teacher learning institutions can be highlighted.

As it is with cooperative learning, assessing collaborative learning activities could be difficult and undesirable with students. In group work, care shall be exercised to compensate for participant motivation levels for response time. To mediate disagreements about this, average or maximum gaps are accommodated in evaluated outputs affected by less able to engage group members. It could be contended that the collaborative nature of learning renders this problem largely obsolete. If all team members are working along, the same concern is solved instead of dividing up the process for response time. Then different levels of involvement by individual persons will have a greater effect on the individual instead of the group.

The four statements have been questioned by the English Football League (EFL) students in order to assess their view of the implementation of knowledge creation practices (see Table 3). A very huge percentage $(82.99 \%)$ of students in grades agreed that trainings or presentations create knowledge, while $79.56 \%$ agreed that standards generate knowledge sharing practices in EFL classrooms. In evaluation, $65.19 \%$ of classroom outside students indicated that extracurricular activities help them learn, while $89.12 \%$ agreed that standard classroom instruction to students as individuals is learned in EFL classes. The performance analysis for the knowledge management procedures in EL classroom result analysis is shown in Figure 9. The $x$-axis units are represented for the group of students in the classroom based on the dataset male or female.

The use of technology can greatly improve collaborative learning (refer to Table 3 ). In recent times, the sector of 
TABLE 3: Students' perceptions of organizational knowledge management procedures in EL classrooms.

\begin{tabular}{lcccc}
\hline Items & Mean & Grade & $\begin{array}{c}\text { Knowledge sharing } \\
\text { practices }\end{array}$ & $\begin{array}{c}\text { Improve or encourage } \\
\text { collaborative education }\end{array}$ \\
\hline Students to the neighborhood from outside school/college & 3.87 & 82.89 & 79.56 & 85.34 \\
From classroom instruction to students as individuals & 3.43 & 85.34 & 89.12 & 83.69 \\
$\begin{array}{l}\text { From other organizations or individuals outside of } \\
\text { the school/college }\end{array}$ & 3.75 & 74.12 & 67.54 & 76.23 \\
Event outside the classroom & 3.82 & 62.45 & 65.19 & 67.89 \\
\hline
\end{tabular}

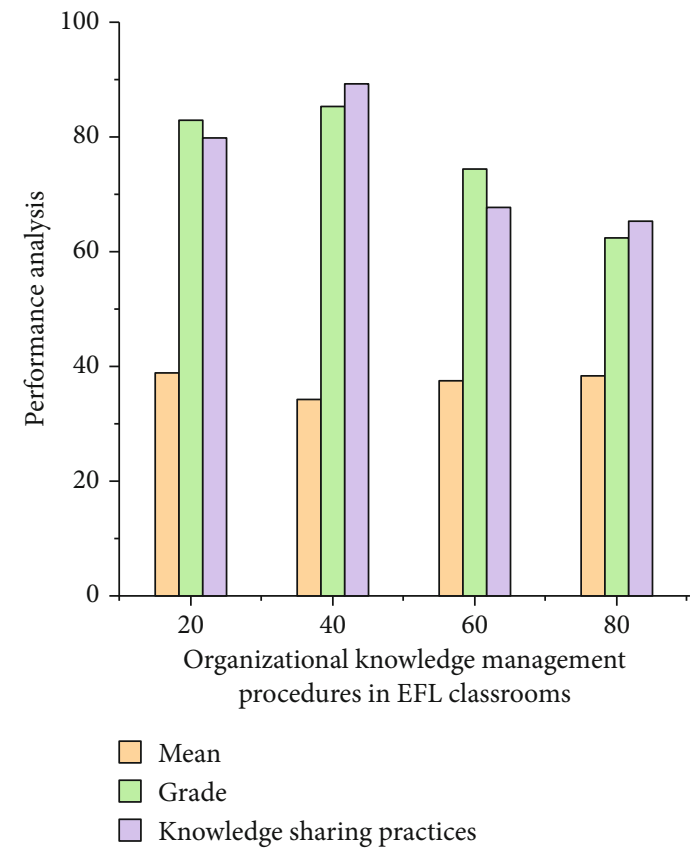

Figure 9: Students' perceptions of organizational knowledge management procedures in EL classrooms.

collaborative learning has grown rapidly. With the introduction of tablet devices as well as connected devices, collaborative activities could be enabled in a variety of ways using equipment. As it is with student engagement, assessing collaborative learning activities can also be difficult and undesirable with students. In group work, care shall be exercised to compensate for participating member motivation levels, to help resolve disputes about this, and/or to accommodate gaps in evaluated outputs induced by less able to share the knowledge and practices to engage team members.

\section{Conclusion}

In this study, collaborative learning information based on knowledge management in English teaching is performed. The concept of knowledge management plays a significant guiding role in the implementation of collaborative learning, knowledge exchange and sharing, and the evaluation of collaborative learning results. Applying collaborative information learning to English teaching and learning can produce better teaching results. The combination of groups in collab- orative learning should be scientific, systematic, and reasonably allocated in accordance with learning habits, students' personalities, and learning situations. This study implemented the multiprocessor learning algorithm (MLA) with support vector machine (SVM) over the student response dataset. The students' responses indicate that the students have gained a minimum increase of two percent of knowledge with the English education-learning technology from collaborative-based learning approach compared to the traditional learning method.

\section{Data Availability}

All data included in this study are available upon request from the corresponding author.

\section{Conflicts of Interest}

There are no conflicts of interest.

\section{References}

[1] K. A. Nihuka and J. Voogt, "Collaborative e-learning course design: impacts on instructors in the Open University of Tanzania," Australasian Journal of Educational Technology, vol. 28, no. 2, pp. 232-248, 2012.

[2] D. Tang, R. Zhu, and J. Tang, "Product design knowledge management based on design structure matrix," Advanced Engineering Informatics, vol. 24, no. 2, pp. 159-166, 2010.

[3] X. Wu, X. Yuan, C. Duan, and J. Wu, "A novel collaborative filtering algorithm of machine learning by integrating restricted Boltzmann machine and trust information," Neural Computing and Applications, vol. 31, no. 9, pp. 4685-4692, 2019.

[4] R. J. Torraco, “A theory of knowledge management," Philosophical Books, vol. 3, no. 1, pp. 1-3, 2017.

[5] F. Ndumbaro and S. Mutula, "Applicability of solitary model of information behavior in students' collaborative learning assignments," New Library World, vol. 120, no. 3/4, pp. 190207, 2019.

[6] I. J. Mulder, "Understanding designers designing for understanding: collaborative learning and shared understanding in video-based communication," Telematica Instituut, vol. 8, no. 2, pp. 237-237, 2017.

[7] M. Handzic, A. Lagumdzija, and A. Celjo, "Auditing knowledge management practices: model and application," Knowledge Management Research \& Practice, vol. 6, no. 1, pp. 9099, 2008.

[8] L. Schnaubert and D. Bodemer, "Providing different types of group awareness information to guide collaborative learning," 
International Journal of Computer-Supported Collaborative Learning, vol. 14, no. 1, pp. 7-51, 2019.

[9] M. Cabezas, S. Casillas, and A. Hernandez, "A case study on computer supported collaborative learning in Spanish schools," Journal of Information Technology Research, vol. 9, no. 2, pp. 89-102, 2016.

[10] P. Centobelli, R. Cerchione, and E. Esposito, “Aligning enterprise knowledge and knowledge management systems to improve efficiency and effectiveness performance: a threedimensional Fuzzy-based decision support system," Expert Systems with Applications, vol. 91, pp. 107-126, 2018.

[11] S. Y. Cho, J. Happa, and S. Creese, "Capturing tacit knowledge in security operation centres," IEEE Access, vol. 8, pp. 4202142041, 2020.

[12] M. Tabatabaei, A. Afrazeh, and A. Seifi, "A game theoretic analysis of knowledge sharing behavior of academics: bi-level programming application," Computers \& Industrial Engineering, vol. 131, pp. 13-27, 2019.

[13] P. Altanopoulou and N. Tselios, "Big five personality traits and academic learning in wiki-mediated collaborative activities," International Journal of Distance Education Technologies, vol. 16, no. 3, pp. 81-92, 2018.

[14] D. D. Panggabean, I. Irfandi, and J. Sinuraya, "Improving of the student learning in lectures of General Physics I by collaborative learning model based on scientific approach," Jurnal Pendidikan Fisika Indonesia, vol. 13, no. 2, pp. 94-101, 2017.

[15] M. R. Maraqa, G. Omari, and M. A. Jarrah, "The impact of knowledge management infrastructure on the innovation process and products: the mediating role of knowledge management technologies and mechanisms," Management Science Letters, vol. 11, no. 2, pp. 261-270, 2021.

[16] Y. Peng, Y. Zhao, and J. Zhang, "Two-stream collaborative learning with spatial-temporal attention for video classification," IEEE Transactions on Circuits \& Systems for Video Technology, vol. 29, no. 3, pp. 773-786, 2019.

[17] J. Janssen and P. A. Kirschner, "Applying collaborative cognitive load theory to computer-supported collaborative learning: towards a research agenda," Educational Technology Research and Development, vol. 68, no. 2, pp. 783-805, 2020.

[18] H. Mora, M. T. Signes-Pont, A. Fuster-Guilló, and M. L. Pertegal-Felices, "A collaborative working model for enhancing the learning process of science \& engineering students," Computers in Human Behavior, vol. 103, pp. 140-150, 2020. 